\title{
Inguinal bladder hernia associated with vesico-ureteric reflux
}

\author{
J.G. Noble, T.J. Christmas, C.R. Chapple and D. Rickards ${ }^{1}$ \\ The Departments of Urology and ' Radiology, The Middlesex Hospital, Mortimer Street, \\ London WIN $8 A A, U K$
}

\begin{abstract}
Summary: The urinary bladder is frequently found as a component of inguinal herniae. This report describes a case of 'bladder hernia' associated with vesico-ureteric reflux. The current methods of investigation and subsequent treatment for this condition are reviewed along with the possible underlying cause of vesico-ureteric reflux in this case.
\end{abstract}

\section{Introduction}

The bladder is one of a variety of intraperitoneal or extraperitoneal structures that may occasionally be found within inguinal herniae. Large bladder herniae are often associated with urinary symptoms and require careful pre-operative assessment.

Urological investigation commonly incorporates imaging of the upper urinary tract with excretory urography. Intravenous urography (IVU) is nearly always performed in the supine position and consequently most bladder herniae are not detected by this procedure but are incidentally found during herniorrhaphy. ${ }^{1}$ However, voiding cystourethrography with the patient erect will identify most bladder herniae and is the investigation of choice in patients presenting with large inguino-scrotal herniae combined with urinary symptoms. $^{2}$

We present a case of a large bladder hernia associated with vesico-ureteric reflux which predisposed to recurrent urinary tract infections.

\section{Case report}

A 47 year old man was referred to the urology department complaining of frequency of micturition, and a poor urinary stream with associated recurrent urinary tract infections. Examination revealed bilateral direct inguinal herniae, larger on the right side and a small clinically benign prostate. IVU showed normal upper tracts, a trabeculated bladder with a right-sided inguinal hernia and a moderate post-micturition residue. A video

Correspondence: J.G. Noble, F.R.C.S.

Accepted: 9 September 1991 cystometrogram performed in the erect position confirmed the presence of a large right-sided bladder hernia and demonstrated grade 2 ureteric reflux on the right during the filling phase (Figure 1). There was no detrusor instability during filling but the patient voided with a high detrusor pressure $(77 \mathrm{~cm}$ water), low maximum flow rate $(13 \mathrm{ml} / \mathrm{s})$ and on performing the stop test a positive 'Whiteside trapping sign' (incomplete milk-back of contrast from the prostatic urethra into the bladder on interrupting micturition due to a narrow bladder outlet), indicative of bladder neck obstruction. ${ }^{3}$

The patient underwent bilateral direct inguinal hernia repair and concomitant endoscopic bladder neck incision which resulted in complete symptomatic relief and a subsequent increase in maximum and mean flow rate to $29 \mathrm{ml} / \mathrm{s}$ and $14 \mathrm{ml} / \mathrm{s}$ respectively. There was no evidence of vesico-ureteric reflux on a micturating cystogram performed 9 months following the procedure.

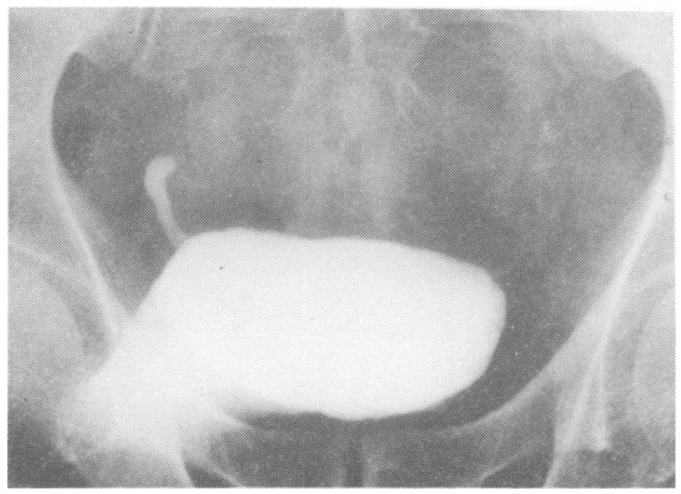

Figure 1 Right vesico-ureteric reflux associated with a bladder hernia. 


\section{Discussion}

Herniation of the urinary bladder is not uncommon and may occur in up to $10 \%$ of all inguinal hernia in men over 50 years of age. ${ }^{4}$ Although most bladder herniae are either inguinal or femoral, the bladder when distended can herniate into any pelvic or abdominal cavity within its reach. Bladder outlet obstruction is a well-recognized cause for direct inguinal bladder herniae. The mechanism of this association is thought to be due to the increased abdominal pressure generated during voiding. Inguinal bladder herniae may be classified as paraperitoneal, extraperitoneal or intraperitoneal; paraperitoneal herniae are the most common with extraperitoneal and intraperitoneal herniae occurring less frequently. ${ }^{5}$

With large bladder herniae the most common associated urinary symptoms are double micturition and those associated with bladder outflow obstruction. Stagnation of urine within a bladder hernia sac often predisposes to recurrent urinary tract infection. ${ }^{6}$

In this case bladder herniation was associated with vesico-ureteric reflux which may have further contributed to the pathogenesis of the recurrent

\section{References}

1. Barquin, O.P. \& Madsden, P.O. Scrotal herniation of the lower urinary tract. J Urol 1967, 98: 508.

2. Gomella, L.G., Spires, S.M., Burton, J.M., Ram, M.D. \& Flanigan, R.C. The surgical implications of herniation of the urinary bladder. Arch Surg 1985, 120: 964.

3. Turner-Warwick, R.T. \& Whiteside, C.G. Investigation and management of bladder neck dysfunction. In: Riches, E. (ed.). Modern Trends in Urology, Volume 3. Butterworths, London, 1969, pp. 295-311. urinary tract infections. This phenomenon has not been noted in a review of previous reported cases of bladder hernia. It is possible that the caudal distraction of the bladder base produced by the hernia caused an elongation of the intramural portion of the distal ureter resulting in an increase in the 'vesico-ureteric' angle. This angle is important in the maintenance of the anti-reflux mechanism at the vesico-ureteric junction such that if it is increased to a more obtuse angle the intramural portion of the ureter is less efficient at preventing ureteric reflux. In this patient the recurrent urinary tract infections were completely eradicated following bladder neck incision and routine inguinal herniorrhaphy. Follow up of the patient one year later showed he had not had any further urinary tract infections, he was voiding without problem and had not developed recurrence of his hernia.

This case demonstrates the value of voiding cystourethrography in the pre-operative assessment of large inguino-scrotal herniae associated with urinary symptoms and adds further support to the suggestion that a more acute vesico-ureteric angle of entry of the ureter into the bladder is important for prevention of vesico-ureteric reflux.

4. Iason, A.H. Repair of urinary bladder herniation. Am J Surg 1944, 63: 69-77.

5. Thompson, J.E., Taylor, J.B., Nazarian, N. \& Bennion, R.S. Massive inguinal scrotal bladder hernias: a review of the literature with two new cases. $J$ Urol 1986, 136: 1299-1301.

6. Liebeskind, A.L., Elkin, M. \& Goldman, S.H. Herniation of the bladder. Radiology 1973, 106: 257-262. 